\title{
Assessment of the Advantages of Static Shoulder FSW for Joining Aluminium Aerospace Alloys
}

DOI:

10.4028/www.scientific.net/MSF.783-786.1770

\section{Document Version}

Accepted author manuscript

Link to publication record in Manchester Research Explorer

\section{Citation for published version (APA):}

Wu, H., Chen, Y. C., Strong, D., \& Prangnell, P. (2014). Assessment of the Advantages of Static Shoulder FSW for Joining Aluminium Aerospace Alloys. Materials Science Forum, 783, 1770-1775.

https://doi.org/10.4028/www.scientific.net/MSF.783-786.1770

\section{Published in:}

Materials Science Forum

\section{Citing this paper}

Please note that where the full-text provided on Manchester Research Explorer is the Author Accepted Manuscript or Proof version this may differ from the final Published version. If citing, it is advised that you check and use the publisher's definitive version.

\section{General rights}

Copyright and moral rights for the publications made accessible in the Research Explorer are retained by the authors and/or other copyright owners and it is a condition of accessing publications that users recognise and abide by the legal requirements associated with these rights.

\section{Takedown policy}

If you believe that this document breaches copyright please refer to the University of Manchester's Takedown Procedures [http://man.ac.uk/04Y6Bo] or contact uml.scholarlycommunications@manchester.ac.uk providing relevant details, so we can investigate your claim.

\section{OPEN ACCESS}




\title{
Assessment of the Advantages of Static Shoulder FSW for Joining Aluminium Aerospace Alloys
}

\author{
Hao $\mathrm{Wu}^{1 \mathrm{a}}$, Ying-Chun Chen ${ }^{1 \mathrm{~b}}$, David Strong ${ }^{1 \mathrm{c}}$, and Phil Prangnell ${ }^{1 \mathrm{~d}}$ \\ ${ }^{1}$ School of Materials, Univ. of Manchester, Manchester M13 9PL, UK \\ ahao.wu-5@postgrad.manchester.ac.uk, byingchun.chen@manchester.ac.uk, \\ cdavid.strong@manchester.ac.uk, ${ }^{\mathrm{d}}$ philip.prangnell@manchester.ac.uk.
}

Keywords: Friction Stir Welding, Stationary Shoulder, AA7050, Thermal Modelling, Distortion

\begin{abstract}
Stationary (or Static) Shoulder Friction Stir Welding (SS-FSW) is a variant of FSW that was developed primarily to improve the weldability of titanium alloys by reducing the through thickness temperature gradient. Surprisingly, SS-FSW has been largely ignored by the Al welding community because it is widely supposed a rotating shoulder is an essential aspect of the process and that the higher conductivity means the surface heating effect of the shoulder is generally beneficial. In the work presented it is shown that SS-FSW has major advantages when welding high strength aluminium alloys; including a reduction in the heat input, a massive improvement in surface quality, and a narrower and more symmetric temperature distribution, which leads to narrower welds with a reduced heat affected zone width and lower distortion. The reasons for these benefits are discussed based on a systematic study aimed at directly comparing both processes.
\end{abstract}

\section{Introduction}

Friction Stir Welding (FSW) is now a well-established process that is widely used to join aluminium alloys, owing to the excellent weld properties that can be obtained [1]. The technology was original developed in the UK by the TWI [1] and involves translating a rotating tool along the join line between two butted plates, which forges the two weld members together without melting. Stationary (Static) Shoulder Friction Stir Welding (SS-FSW) is a variant on FSW that was developed more recently, primarily to improve the weldability of titanium alloys [2,3]. The method was originally invented because in conventional FSW the low thermal conductivity of titanium results in the rotating tool shoulder creating a severe temperature gradient through the plate thickness [2]. However, it could be envisaged that with all materials SS-FSW would be advantageous when welding thicker gauges. This is because in conventional FSW heat is generated predominately under the shoulder, where it is limited by melting at the contact surface, and thus with thicker gauges it is not normally possible to maintain a high enough temperature at the base of the weld to avoid pin failures unless a low travel speed is used. Furthermore, in principle SS-FSW should provide several additional advantages over the conventional method; i) a non-rotating shoulder irons the surface and leads to an improvement in surface quality [2], ii) the shoulder acts as a heat sink, rather than a source, so that the heat distribution becomes narrower at the top surface and more symmetric about the plate mid plane, which should lead to narrower welds with a reduced heat affected zone width, as well as lower levels of distortion. However, with a conventional tool the power generated by the pin at a fixed rpm is typically only $20-30 \%$ of that of the tool shoulder $[4,5]$, so that the same welding conditions are not appropriate for both processes.

Surprisingly, static shoulder FSW has largely been ignored by the aluminium welding community and there is little published in the literature apart from one study, using a AA6061 alloy, where it has been shown that with a static shoulder the texture in the weld zone becomes entirely dominated by the pin [3]. Here we have attempted to compare the two processes in a typical Alaerospace alloy (AA7050) welded at relatively thin gauges $(6 \mathrm{~mm})$ where it might be thought that 
stationary shoulder would offer less benefit. The approach adopted has been to use an identical shoulder and pin geometry for each method and to first understand the relationship between the heat input and the welding parameters, so that both processes can be compared using a rational selection of welding conditions. Modelling has also been used to fit the thermal field for each process and predict the effect on the HAZ shape. We have also considered the surface finish and weld defects that can be specific to the SS-FSW process.

\section{Experimental}

Welds were produced in a $6.3 \mathrm{~mm}$ thick AA7050-T7651 plate in a square butt configuration, using conventional and stationery shoulder tools with identical geometry. The tools both had a shoulder diameter of $18 \mathrm{~mm}$ with a $5.9 \mathrm{~mm}$ long conical, threaded, tri-flat probe that had a diameter of $6.2 \mathrm{~mm}$ and $4 \mathrm{~mm}$ at the root and tip respectively. The conventional tool had a concave shoulder and welding was performed with a $2^{\circ}$ tilt and plunge depth of $0.2 \mathrm{~mm}$. The SS-FSW shoulder was fixed directly to the welding head and the pin rotated within a bearing assembly. The tool was kept vertical and the shoulder had a slight convex radius to allow it to slide. With both processes welding was first performed over a range of conditions to develop torque decay curves with increasing rotation rate, following the approach of Reynolds et al [5] (see below). Torque and translational forces were logged from the welding machine. Thermocouple measurements were made at six locations (top, centre bottom, near the tool and at distances of 10,20,30 mm, at the plate centre line) to provide data for calibration of a thermal model. A finite difference model was used to fit the welds' thermal fields, using a surface ring shaped heat source, to represent the shoulder, and ten increasing diameter cylindrical volume sources to represent the conical probe. The power was distributed in each case in proportion to the surface velocity. For the stationary shoulder the shoulder power was set to a small negative power to represent heat lost to the cold tool.

For selected conditions hardness maps were produced across weld transverse cross sections using an Instron microhardness machine with a $0.5 \mathrm{~kg}$ load. A semi-empirical precipitation hardening model [6], was employed to predict the hardness profiles across the welds. This was achieved by using the modelled weld thermal cycles for locations across the mid-plane of the weld, at intervals of $1 \mathrm{~mm}$ away from the weld line, as an input to the hardness model. Microstructural features were investigated by conventional optical microscopy. A $\mu$-scan SC200 laser profiler was used to measure surface roughness. Weld mechanical properties will be reported at a later date.

\section{Results and Discussion}

In FSW the welding power, $\mathrm{Q}$, is related to the torque, $\mathrm{M}$, by $\mathrm{Q}=\mathrm{M} \omega$, where $\omega$ is the rotation rate $\left(\operatorname{rad~s}^{-1}\right)$ [4]. A simple analytical model for the tool torque [4], adapted for a tapered pin, which assumes a uniform material flow stress across the tool surfaces, can be expressed as:

$$
M=2 \pi \frac{\sigma}{\sqrt{3}}\left[\frac{1}{3}\left(1-\delta_{1}\right)\left(r_{s}^{3}-r_{p t}{ }^{3}\right)+\left(\frac{1}{3} m^{2} h^{3}+m h^{2} r_{p b}+h r_{p b}^{2}\right)+\frac{1}{3} r_{p b}^{3}\right]
$$

In equ (1) the first term represents the contribution from the shoulder, the second the probe conical surface, and the third the probe base. The geometric terms $r_{s}, r_{p t}, r_{p b}$, and $h$ are the shoulder, probe root, and tip radii, and probe height respectively, $m$ is the taper gradient of the probe, $\sigma$ is the materials flow stress, and $\delta$ is a slip parameter. As has been proposed by Cui et al [7], this relationship can be used to predict the theoretical torque at zero rpm, when the material will be at room temperature. This point can then be used to fit an exponential torque - rotation rate decay curve to experimental data (Fig. 1a) from which the welding power curve can be derived (Fig. 1b).

As has been previously noted [5] there is a smaller dependence on the travel speed and the torque curves are dominated by the rotation rate. The fitted curves show, unsurprisingly, that for a given rotation rate the static shoulder tool developed a much lower torque, and hence welding power, than 
the standard approach, with approximately $70 \%$ of the power being provided by the shoulder at low $\mathrm{rpm}$, but this difference reduced to about $50 \%$ at high rpm where the torque reaches a lower limit.
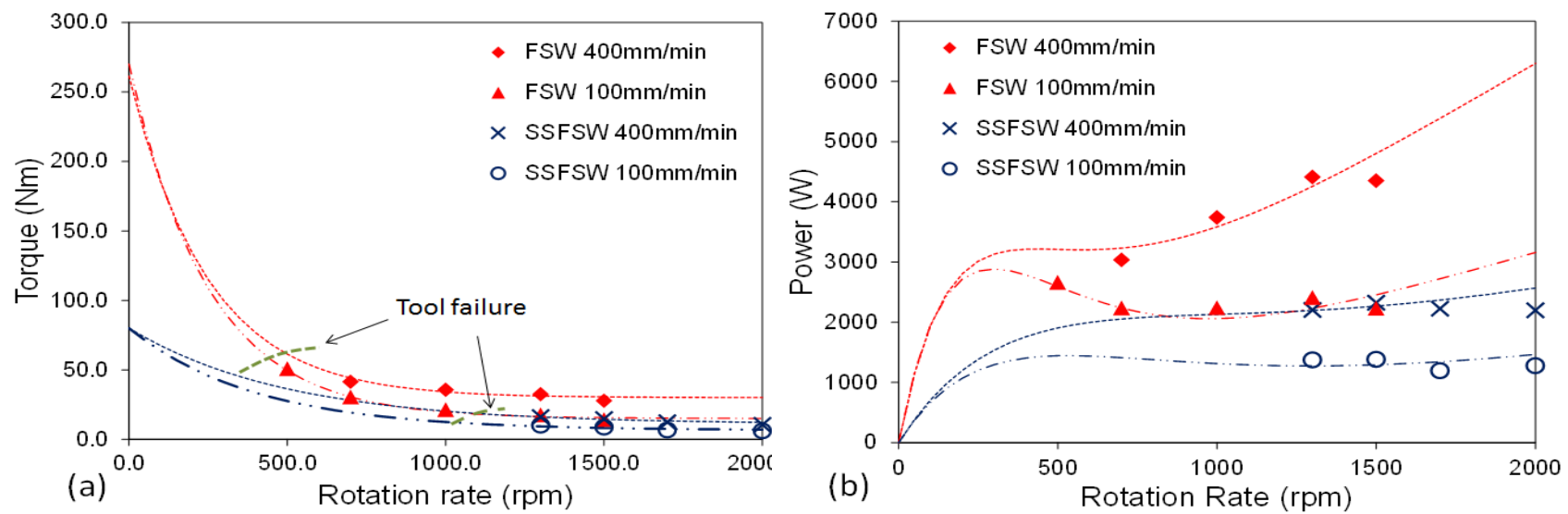

Fig. 1 (a) Exponential torque decay curves as a function of rotation rate, $\omega$, fitted to experimental data and (b) the related welding power curves. The lower limits for pin failure are given in (a).

An important consideration when comparing static shoulder to conventional FSW is thus what welding conditions to use, because welds produced at the same travel speed will not have the same optimum rotation rate, owing to the different tool surface velocities, surface area, and therefore welding power. In Fig. 1 the lower limit to the process window is indicated for the two techniques, where tool failures occurred through pin shear at high torque levels when the welds were too cold. As can be seen, this threshold occurred at a much higher RPM for the SS-FSW process (e.g. 1000 rpm compared to $500 \mathrm{rpm}$ for the FSW tool at $400 \mathrm{~mm} \mathrm{~min}^{-1}$ ). In comparison, with too high a rotation rate welding was limited by surface melting in the case of the FSW process.

In the work presented below we initially attempted to compare the two process variants on the basis of the same welding power, at the same high travel speed of $400 \mathrm{~mm} \mathrm{~min}^{-1}$ that still gave a reasonable process window, which would result in the same heat input. However, this highlighted an advantage of SS-FSW in that it was not possible to produce welds with as low a power with the FSW process as can be achieved by SS-FSW, without pin failures, because the much lower RPM necessary with FSW resulted in the material at the base of the weld becoming too cold. For FSW the tool was therefore run at the rotation rate for the same travel speed that gave satisfactory tool life with the minimum power. At a travel speed of $400 \mathrm{~mm} \mathrm{~min}^{-1}$ this gave optimum welding conditions for comparison purposes, of 1500 RPM and 700 RPM for SS-FSW and FSW respectively, which resulted in a $\sim 30 \%$ lower welding power for the SS-FSW tool.

Surface finish/ defects. One of the important advantages of static shoulder welding is the far superior surface finish it produces relative to FSW and indeed, any other known welding process. This primarily results from the hot ironing effect generated by the static shoulder, which with aluminium gives a comparable finish to that obtained from a polished extrusion die. Examples of laser scanning measurements in Fig. 2 indicate that the surface roughness, relative to that with the standard rotating shoulder, was reduced by over an order of magnitude and hardly detectable. Furthermore, the depression of the surface due to the shoulder plunge required to make a defect free weld was also substantially reduced to only $0.02 \mathrm{~mm}$ compared to $0.6 \mathrm{~mm}$ for the standard tool.

However, one issue specific to the stationary shoulder approach was observed, in that cracking defects where found close to the surface under certain welding conditions - examples of which are shown in Fig. 2c. These flaws are caused by a similar phenomenon seen in extrusion of aluminium alloys, termed speed cracking, and occur due to a combination of sticking to the die surface and grain boundary tearing when the material becomes over heated. 
(a)
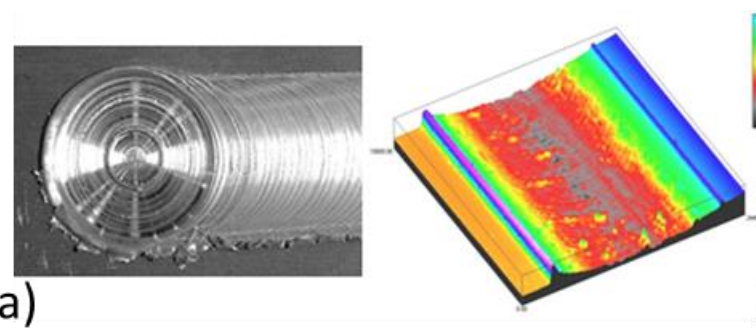

(b)
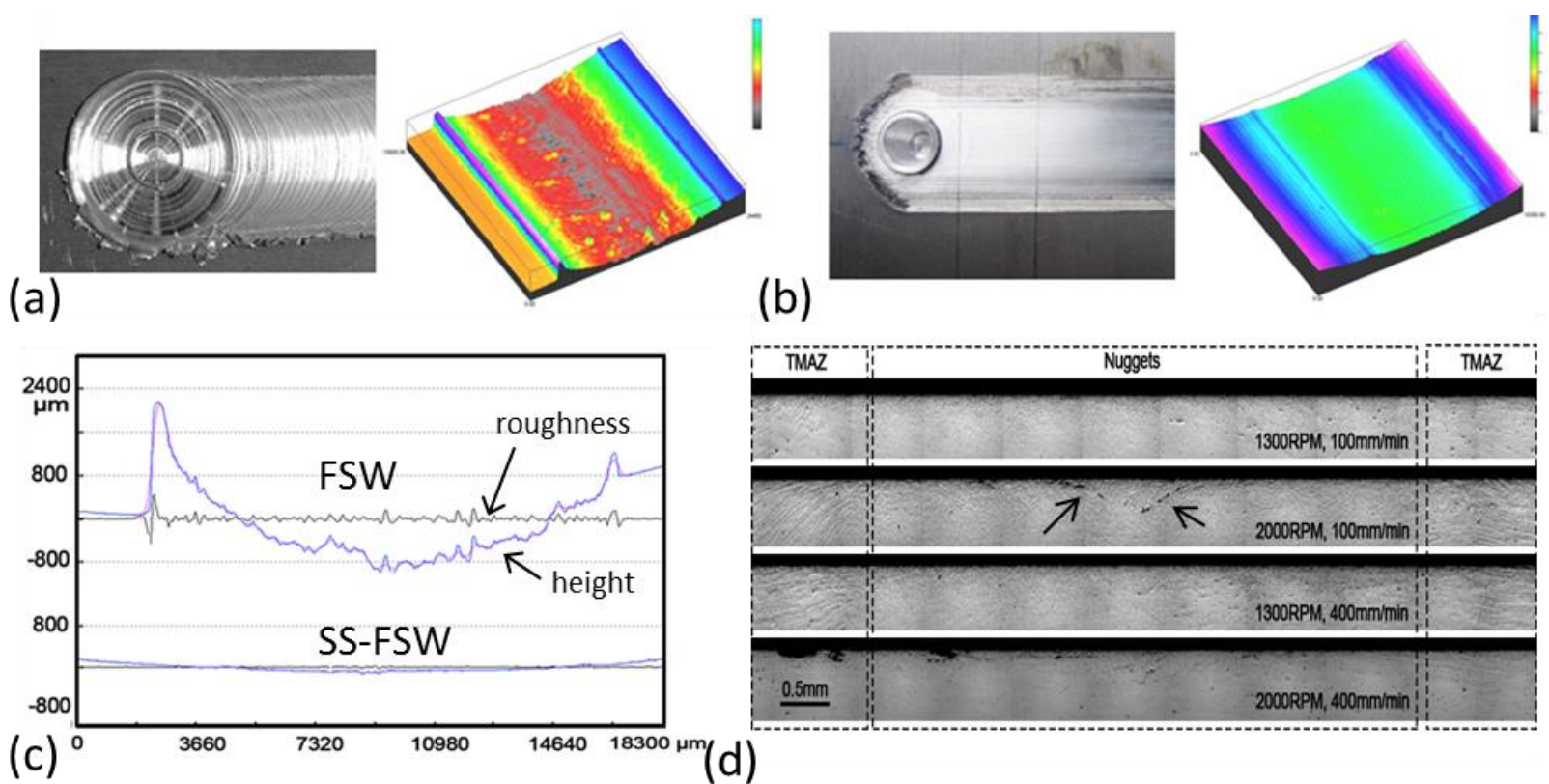

(d)

Fig. 2 The effect of SS-FSW on roughness showing laser surface height profiles for (a) FSW and (b) SS-FSW and (c) averaged profiles across both welds produced under optimum conditions. In (d) a surface defect is shown related to the cold static shoulder in the SS-FSW process.
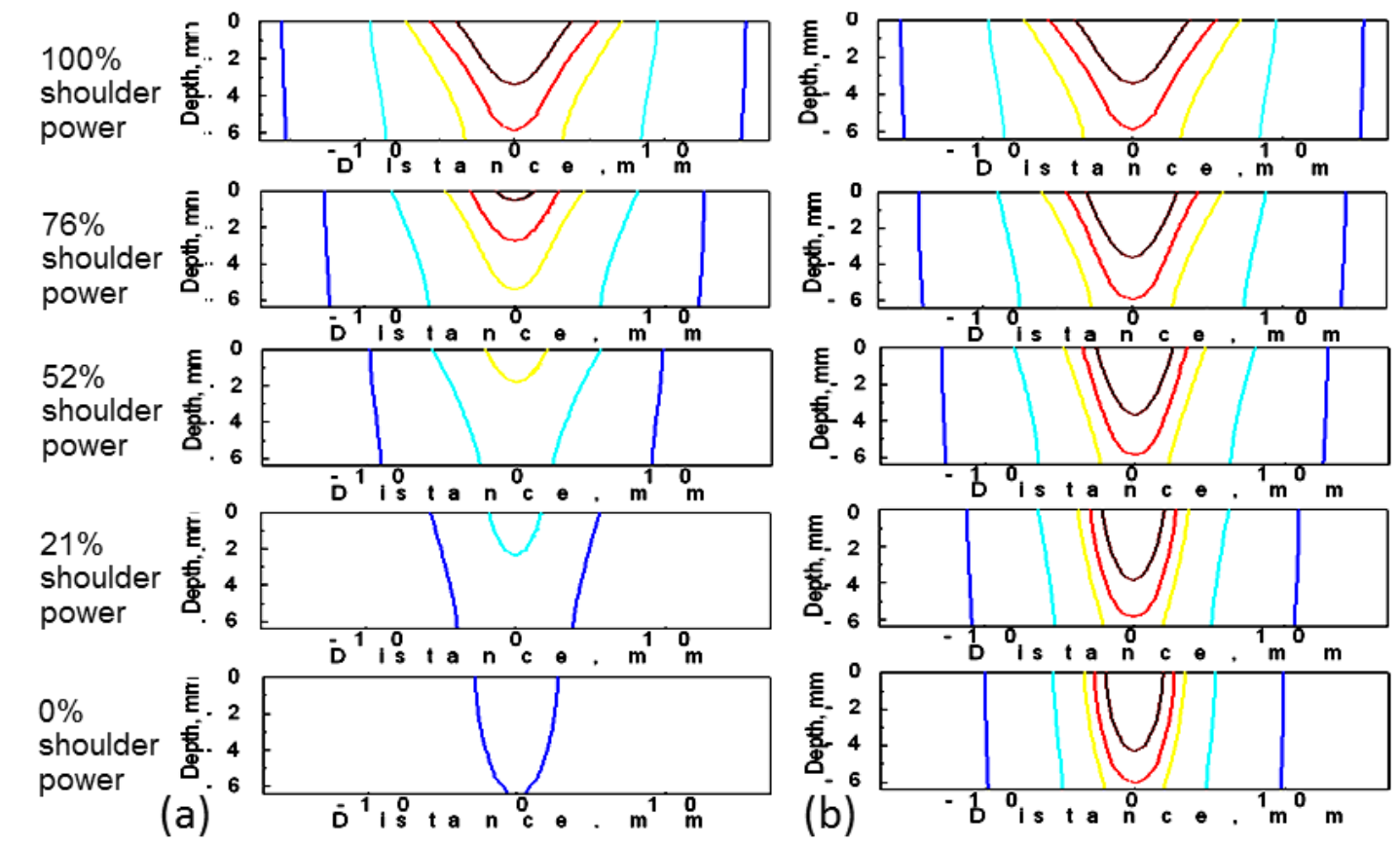

Fig. 3 Model simulations showing the effect of progressively reducing the heat input from the shoulder on the thermal field found in FSW; in (a) the shoulder power was reduced while maintaining a constant probe power and in (b) the probe power was increased to maintain the same temperature at the base of the probe $\left(450^{\circ} \mathrm{C}\right)$ as the shoulder power was reduced to zero.

Temperature distribution. The thermal model was used to simulate the effect of progressively reducing the heat input from the shoulder, on the thermal field found in FSW, to the case where there is no heat input from a static shoulder (Fig. 3). This was achieved by fitting the thermal model to temperature measurements for the FSW and SS-FSW processes and then exploring two scenarios; i) where the shoulder power was reduced while maintaining a constant probe power and ii) where the probe power was increased (i.e. by increasing the rotation rate) as the shoulder power 
was reduced to maintain the same temperature at the base of the probe. For this later case the $450^{\circ} \mathrm{C}$ isotherm was selected. It can be seen from Fig. 3a that by reducing the heat input contribution from the shoulder, although the thermal field becomes narrower and more parallel, the weld rapidly becomes too cold. In comparison, if the power generated by the probe is increased to compensate for the loss of the shoulder rotation it is evident that, despite the higher pin heat input, the thermal field still becomes narrower at the top of the weld and more uniform through the plate thickness.

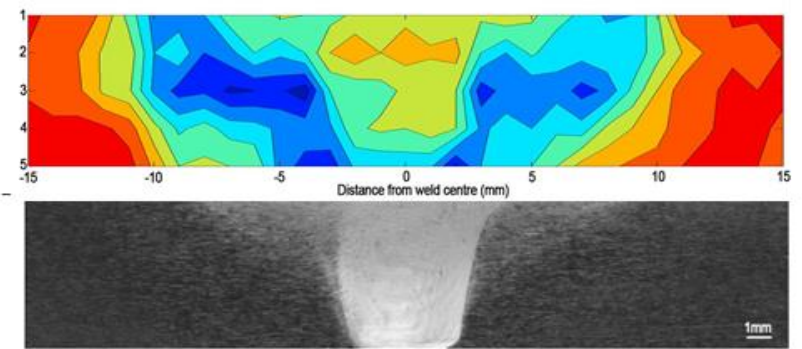

(a)

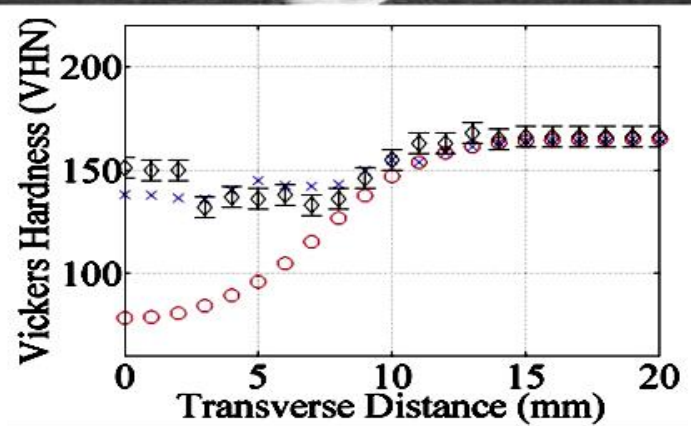

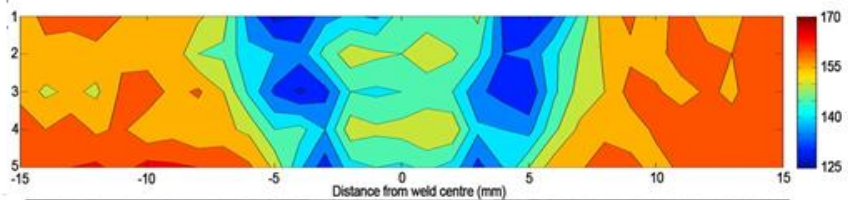

(b)
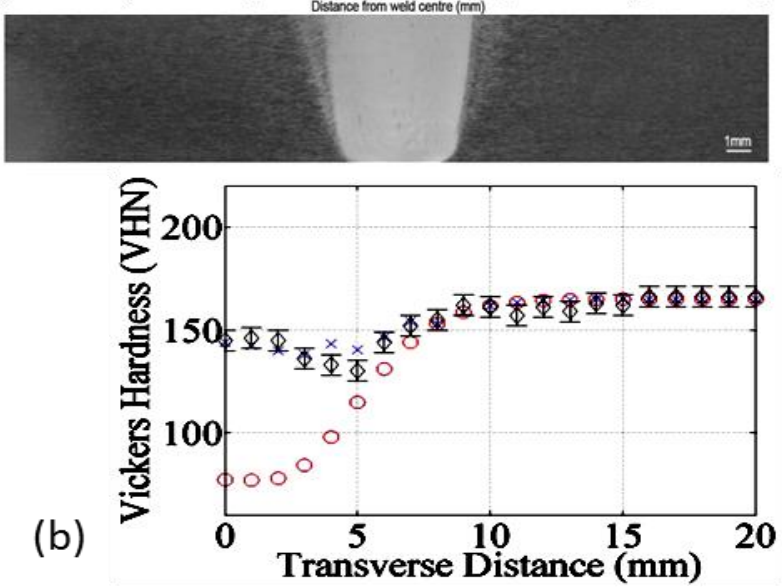

Fig. 4 Hardness measurements and model predictions for the two processes, when welding under optimum conditions, showing (top to bottom) measured hardness maps, macro views of the weld profiles, and predicted and measured hardness profiles at the plate mid plane; (a) with a FSW tool at $700 \mathrm{rpm}$ and (b) a SS-FSW tool at 1,500 rpm (both at $400 \mathrm{~mm} \mathrm{~min}^{-1}$ ).

Hardness distribution. In high strength Al-alloys it is well known that the hardness distribution is dominated by the state of matrix precipitation, which in FSW is largely controlled by the local thermal cycle and in particular the peak temperatures experienced across the weld zones [5,6]. In heat-treatable alloys there are generally two competing effects; softening caused by coarsening, transformation and dissolution of strengthening phases, and post weld natural ageing which can recover much of the strength lost if the local temperature exceeds that required for solution treatment of the alloy, provided there is a sufficient cooling rate during welding [6]. This normally leads to a ' $\mathrm{W}$ ' shaped hardness profile, where the centre of the nugget zone is hot enough to become solutionised and the hardness minima correspond to the positions where substantial overageing has occurred, but the temperature was not high enough for sufficient solute to be retained in solution for significant post weld-natural ageing (typically $~ 350 \mathrm{C}$ ) [6]. This effect can be seen in the weld hardness predictions made across the plate mid plane in Fig. $4 \mathrm{~b}$ for both processes, where predictions are given for the hardness immediately after welding and following post-weld natural ageing. The hardness minima position is normally found near the TMAZ/HAZ boundary, but can shift in or out depending on the heat input and travel speed [6].

In Fig. 4a full transverse cross-section 2D hardness maps are shown measured from welds produced with the FSW and SS-FSW tools, under the optimum conditions of 700 and $1500 \mathrm{rpm}$ at $400 \mathrm{~mm} \mathrm{~min}^{-1}$, respectively. In the case of the standard weld the bands of minimum hardness exhibit a $\mathrm{V}$ shape, due to the majority of the heat input being provided by the tool shoulder. The top of the weld was also clearly much hotter than the base and its hardness has thus recovered more by natural ageing within the weld nugget. In contrast, in the weld produced with the static shoulder the bands of minimum hardness are nearly vertical and the maximum HAZ width is $40 \%$ less, because of the absence of shoulder rotation, which narrows the thermal field at the top surface. There is also a 
lower reduction in through-thickness hardness within the weld nugget, which is close to being symmetrical around the plate mid-plane.

Distortion. The effect of a lower heart input and a narrower and more uniform thermal field with depth on post-weld distortion is shown in Fig. 5, where it can be seen the butterfly distortion caused by transverse tensile stresses is reduced in the static shoulder weld.
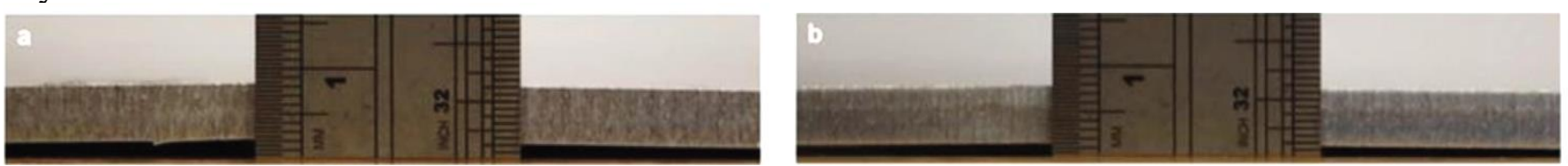

Fig. 5 Comparison of butterfly distortion in (a) FSW and (b) SS-FSW, under optimum conditions

\section{Conclusions}

The systematic study above has shown that SS-FSW is a fundamentally better process than conventional FSW when welding thicker materials above $\sim 5 \mathrm{~mm}$. In high strength Al-alloys SSFSW can produce superior welds at similar translation rates to the conventional process. The SSFSWs can be produced with a lower heat input, which is more uniform through thickness, and have an exceptional surface finish, with little reduction in section thickness, as well as a narrower weld profile, which results in lower levels of distortion and a reduced HAZ width. This improvement is expected to be obtained across all sections thicker than that studied where the role of the heat generated by the shoulder, becomes increasingly irrelevant. In fact, logic would suggest the conventional approach of 'one tool fits all' does not give optimum conditions for FSW. Welding without a shoulder is better for thick sections, whereas a rotating shoulder without a pin is probably better for thin gauges $(<1 \mathrm{~mm})$ and a conventional tool is only appropriate for intermediate thicknesses.

Acknowledgements: We are grateful for financial support provided by EPSRC through LATEST2, (EP/G022402/1) and the Metallic Systems CDT (EP/G036950/1) as well as to Dr. Joe Robson for assistance with hardness modelling.

\section{References}

[1] P. L. Threadgill1, A. J. Leonard, H. R. Shercliff and P. J. Withers, Friction stir welding of aluminium alloys, Int. Materials Reviews 54 (2009) 49-93.

[2] M.J. Russell, M.E. Nunn, J. Martin, Recent developments in the stationary shoulder FSW of Titanium alloys, 7th Int. Symp. on Friction Stir Welding, Japan, 2008, pub. TWI, 10B.

[3] M.M.Z. Ahmed, B.P. Wynne, W.M. Rainforth and P.L. Threadgill, Through-thickness crystallographic texture of stationary shoulder FSW aluminium, Scripta Mater. 64 (2011) 45-48.

[4] H Schmidt, J Hattel and J Wert, analytical model for the heat generation in friction stir welding, Modelling Simul. Mater. Sci. Eng. 12 (2004) 143-157.

[5] T. Long, W. Tang and A. P. Reynolds, Process response parameter relationships in aluminium alloy friction stir welds, Sci. Technol. Welding and Joining 12 (2007) 311-37.

[6] N. Kamp, A. Sullivan, R. Tomasi, J.D. Robson, Modelling of heterogeneous precipitate distribution evolution during friction stir welding process, Acta Materialia 54 (2006) 2003-2014.

[7] S. Cui, Z.W. Chen, J.D. Robson, A model relating tool torque and its associated power to rotation and forward speeds during FSW, Int. J. Machine Tools \& Manu. 50 (2010) 1023-1030. 